\title{
Fault Diagnostic Method for Pump Running Conditions Based on Process Modeling and Neural Network
}

\author{
T. UCHIYAMA ${ }^{\mathrm{a}, *}$, S. KALLWEIT ${ }^{\mathrm{b}}$ and H. SIEKMANN ${ }^{\mathrm{b}}$ \\ ${ }^{a}$ School of Informatics and Sciences, Nagoya University, Furo-Cho, Chikusa-Ku, Nagoya 464-01, Japan, \\ ${ }^{\mathrm{b}}$ Institute of Hydraulic Turbomachinery and Fluid Mechanics, Technical University of Berlin, Germany
}

(Received 6 September 1996; In final form 15 November 1996)

\begin{abstract}
This paper proposes a fault diagnostic method for pump running conditions. The method is a combination of a process modeling and a classification procedure. The pump head and hydraulic losses in the pipe system are modeled by two equations. The values of the coefficients in the equations are determined from measurable output variables of the pump. Since the pump running conditions affect the coefficient values, they are detected by classifying those values. A multi-layer neural network is employed for the classification. Three running conditions of a drainage pump are clearly detected by this method. The accuracy of detection is improved by increasing the hidden layers and their units in the neural network.
\end{abstract}

Keywords: Fault diagnosis, Process modeling, Neural network, Automatic operation, Drainage pump, Running condition

\section{INTRODUCTION}

Demands for the automatic operation of drainage pump stations have increased in recent years (Friedrichsen, 1993). In the drainage pump, the inlet is occasionally blocked due to the sedimentation of sludge, and the impeller is often impeded by litter suspended in the water. Since pump performance is generally diminished under such faulty running conditions, it is necessary to develop a fault diagnostic method if we are to realize the goal of automatic operations. Previous methods for fault detection have been restricted to direct comparison of measurable output variables, such as the pump head and the flow rate, with fixed threshold values. The faults are, therefore, detected only after the variables have been considerably affected, and the faults are not clearly specified.

Process modeling is now attracting an interest for its possible role in the supervision and fault diagnosis of technical plants (Isermann, 1984; Isermann and Freyermuth, 1991a). Conditions inside the plant are modeled by equations composed of the plant's measurable output variables. The

*Corresponding author. E-mail: uchiyama@info.human.nagoya-u.ac.jp. 
values of the coefficients in the equations are determined from the output variables. Since the coefficient values are affected by conditions inside the plant, the faults occurring in the plant are specified by classifying the coefficient values. Faults in centrifugal pumps, such as cavitation and abrasive wear, were detected by this method (Geiger, 1984; Nold and Isermann; 1988; Isermann and Freyermuth, 1991b). But the classification procedure depends on the supervisor, and the automatization of the diagnosis has not been accomplished.
In this paper, a fault diagnostic method for pump running conditions is proposed, which consists of a process modeling and a classification procedure. The pump head and the hydraulic losses are expressed by two equations. The faults are detected by classifying the values of the coefficients in the equations. For the classification, a multilayer neural network (Rumelhart and David, 1989) is employed to diagnose automatically. This method is applied to a drainage pump station in order to specify the running conditions.

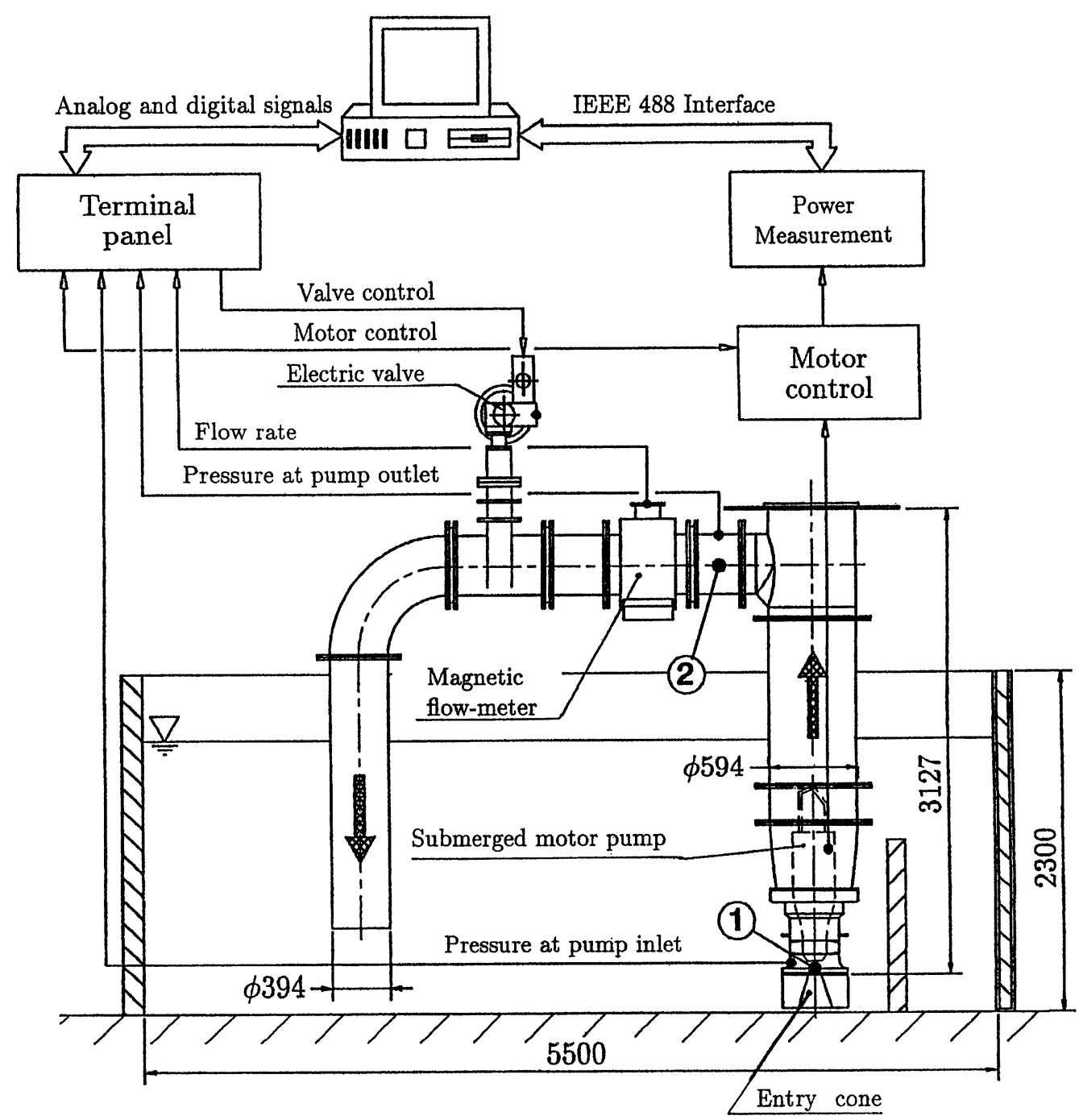

FIGURE 1 Experimental apparatus. 


\section{EXPERIMENTAL APPARATUS AND PROCEDURE}

\section{Experimental Apparatus}

Figure 1 illustrates the general arrangement of the experimental apparatus at the Institute of Hydraulic Turbomachinery and Fluid Mechanics, Technical University of Berlin. A drainage pump having an axial-flow impeller driven by a submersible motor is used. Water from a tank is led to the pump and returned to the tank through a magnetic flow-meter and a regulating valve, successively. The diameter of the discharging pipe is $394 \mathrm{~mm}$. One side of the tank is made of glass to allow observations. Static pressures at the pump inlet 1 and outlet 2 are measured by strain-gauge pressure sensors. The measuring instruments are connected to a personal computer through an $\mathrm{A} / \mathrm{D}$ converter. The data sampling rate is $0.2 \mathrm{kHz}$

The shape and dimensions of the pump inlet and impeller are shown in Fig. 2. The inlet diameter is $350 \mathrm{~mm}$, the number of blades 3 , the inlet blade angle $13.5^{\circ}$, the rotational speed $1470 \mathrm{rpm}$, the flow rate $22.8 \mathrm{~m}^{3} / \mathrm{min}$, the head $5.42 \mathrm{~m}$ and the specific speed $1975\left[\mathrm{rpm}, \mathrm{m}^{3} / \mathrm{min}, \mathrm{m}\right]$. The flow in the impeller is visible through the casing made of transparent acrylic glass. An entry cone with five radial guide vanes is mounted in front of the pump inlet, and five diffuser vanes are installed right behind the impeller. The clearance between the entry cone and the bottom of tank is maintained at $30 \mathrm{~mm}$.

\section{Experimental Procedure}

A fault diagnostic method proposed in this study is applied to detect three running conditions listed in Table I; a normal condition (F0), a blocked condition in the pump inlet (F1), and a condition combined of inlet blockage and impeller impedance (F2). These running conditions are hypothesized to occur in drainage pumps (Friedrichsen, 1993).

For experiment $\mathrm{F} 1$, the entry cone is half covered by a thin plate as shown in Fig. 3(a). For experiment F2, an impeller with vinyl bands on the
TABLE I Pump running conditions

\begin{tabular}{lccc}
\hline & F0 & F1 & F2 \\
\hline $\begin{array}{c}\text { Running } \\
\text { condition }\end{array}$ & Normal & Blocked & $\begin{array}{c}\text { Blocked and } \\
\text { impeded }\end{array}$ \\
\hline
\end{tabular}

pressure and suction sides of one of its blades, as illustrated in Fig. 3(b), is used together with the entry cone as seen in Fig. 3(a). The length of the band is $300 \mathrm{~mm}$, the width $40 \mathrm{~mm}$ and the thickness $0.5 \mathrm{~mm}$.

The experiments are carried out for flow rates ranging from 17.4 to $29.9 \mathrm{~m}^{3} / \mathrm{min}$ under the rated rotational speed.

\section{FAULT DIAGNOSTIC METHOD}

\section{Process Modeling}

On the basis of the process modeling (Geiger, 1984; Nold and Isermann, 1988), the pump head and the hydraulic losses in the pipe system are modeled so that they are expressed by equations composed of measurable output variables such as the pump head, the flow rate and the rotational speed.

It is postulated that the dimensionless head $\psi$ is expressed by the following with use of the dimensionless flow rate $\phi$

$$
\psi=c_{0}+c_{1} \phi+c_{2} \phi^{2}+c_{3} \phi^{3},
$$

where $\psi=H /\left(u_{2}^{2} / 2 g\right), \phi=Q / A_{\mathrm{d}} u_{2}$ and $c_{0}-c_{3}$ are constants.

The head $H$, the flow rate $Q$ and the angular velocity of the impeller $\omega$ are represented by the sum of the time-averaged values $(\bar{H}, \bar{Q}, \bar{\omega})$ and the instantaneous deviations $(\Delta H, \Delta Q, \Delta \omega)$ from the average:

$H=\bar{H}+\Delta H, \quad Q=\bar{Q}+\Delta Q, \quad \omega=\bar{\omega}+\Delta \omega$.

When Eq. (1) is linearlized around the steady operating state of the pump by substituting Eq. (2), the dimensionless form of Eq. (1) including process 


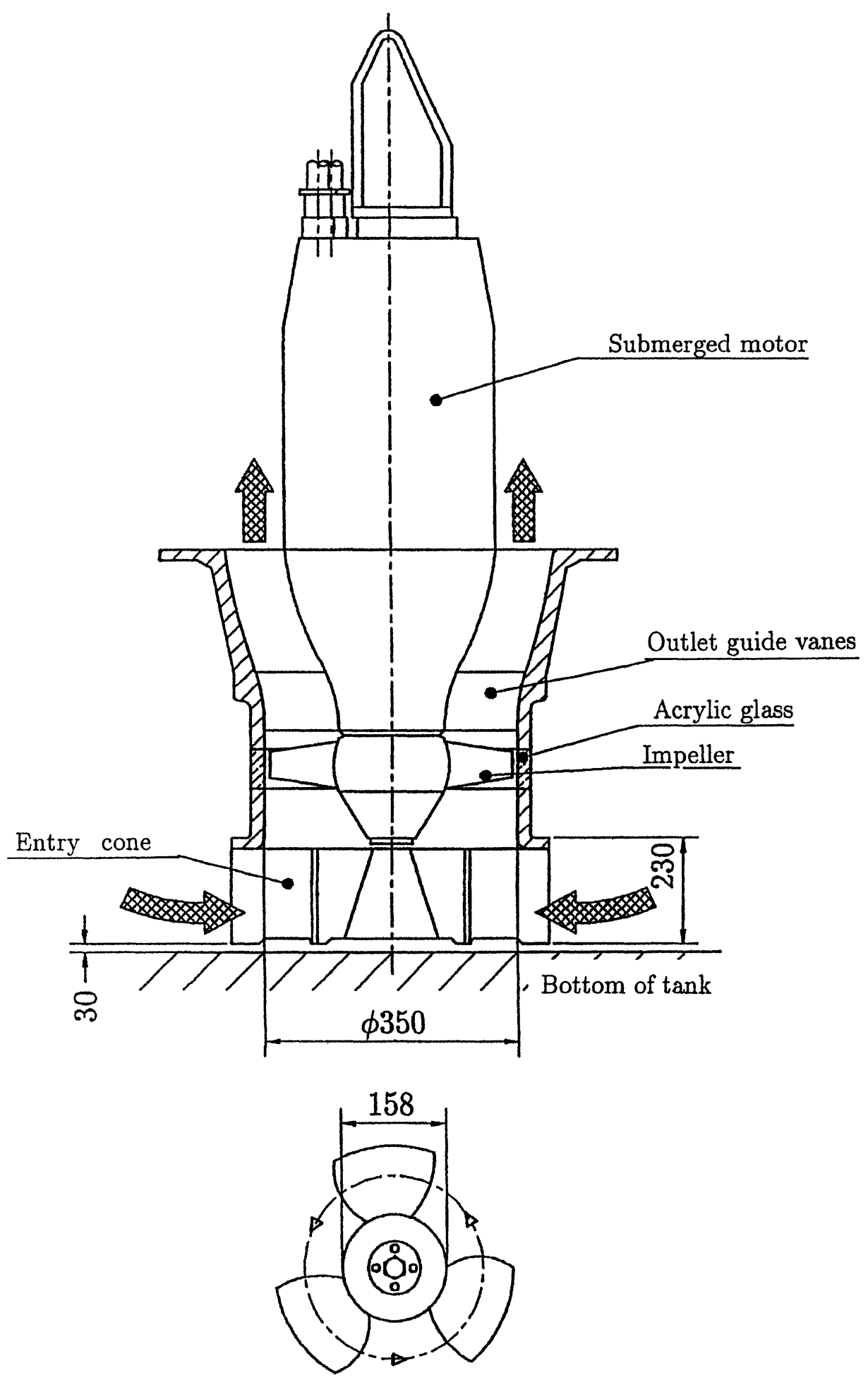

FIGURE 2 Shape and dimensions of drainage pump. 


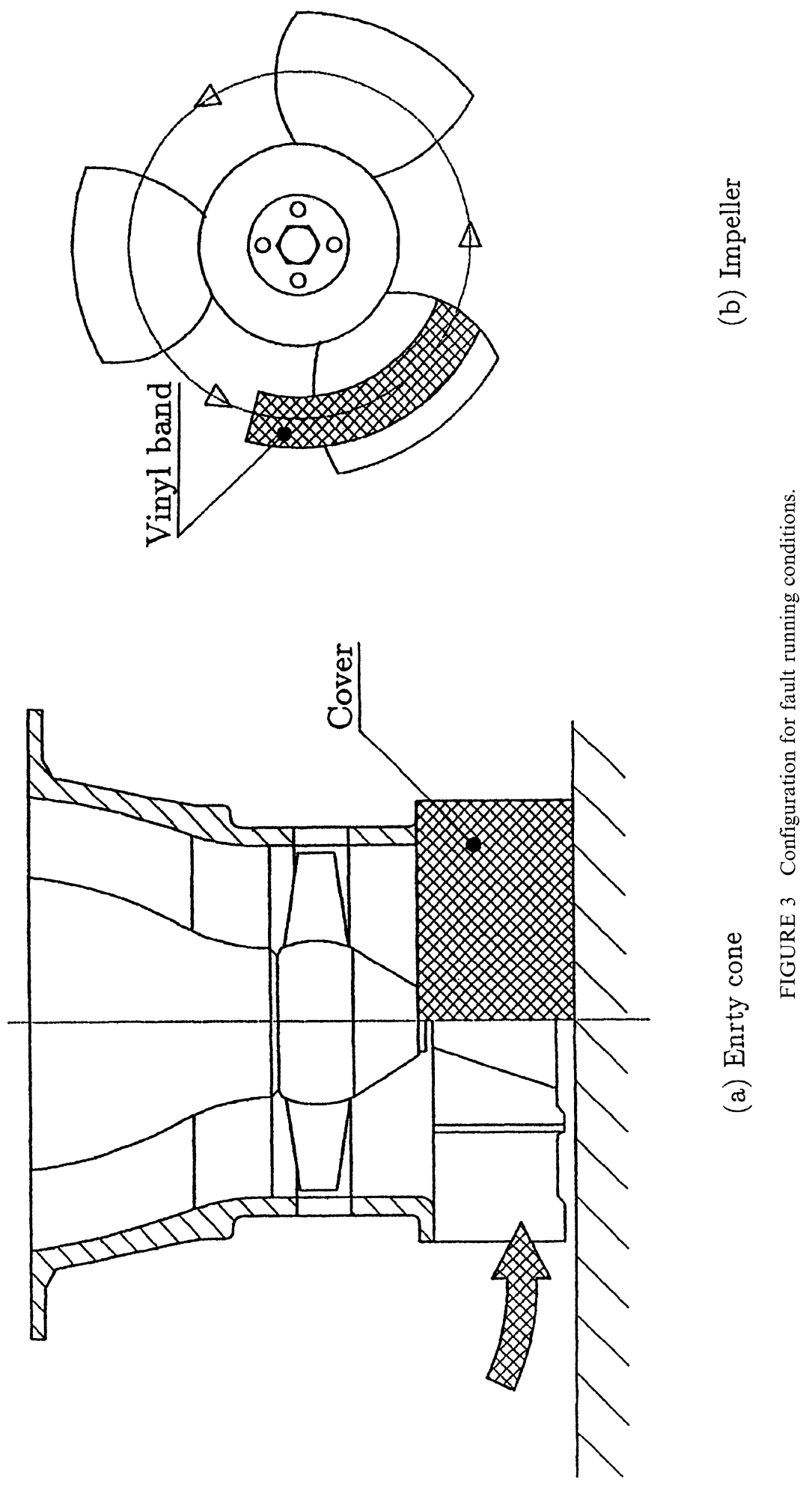


coefficients $C_{\mathrm{r}}$ and $C_{\mathrm{q}}$ is obtained:

$$
\Delta \psi=C_{\mathrm{r}}(\Delta \omega / \bar{\omega})+C_{\mathrm{q}} \Delta \phi,
$$

where

$$
\begin{gathered}
\Delta \psi=\Delta H /\left(u_{2}^{2} / 2 g\right), \quad \Delta \phi=\Delta Q / A_{\mathrm{d}} u_{2}, \\
C_{\mathrm{r}}=2 c_{0}+c_{1} \bar{\phi}-c_{3} \bar{\phi}^{3}, \quad C_{\mathrm{q}}=c_{1}+2 c_{2} \bar{\phi}+3 c_{3} \bar{\phi}^{2} .
\end{gathered}
$$

Here $\bar{\phi}$ denotes the time-averaged value of $\phi$.

Let us consider the losses in the pipe system. The following losses are assumed here; the loss due to the acceleration of fluid $h_{\mathrm{a}}$, the losses caused by the friction on the pipe wall $h_{\mathrm{f}}$ and the mixing of the discharged water in the tank $h_{\mathrm{d}}$, and the losses in the valve $h_{\mathrm{v}}$, in the elbow $h_{\mathrm{e}}$ and at the entry cone $h_{\mathrm{i}}$. They are expressed by the following:

$h_{\mathrm{a}}=\frac{l_{\mathrm{d}}}{g A_{\mathrm{d}}} \frac{\mathrm{d} Q}{\mathrm{~d} t}, \quad h_{\mathrm{f}}=\lambda \frac{l_{\mathrm{d}}}{A_{\mathrm{d}}^{2} D} \frac{Q^{2}}{2 g}, \quad h_{\mathrm{v}}=\frac{\zeta_{\mathrm{v}}}{A_{\mathrm{d}}^{2}} \frac{Q^{2}}{2 g}$,

$h_{\mathrm{e}}=\frac{\zeta_{\mathrm{e}}}{A_{\mathrm{d}}^{2}} \frac{Q^{2}}{2 g}, \quad h_{\mathrm{d}}=\frac{1}{A_{\mathrm{d}}^{2}} \frac{Q^{2}}{2 g}, \quad h_{\mathrm{i}}=\frac{\zeta_{\mathrm{i}}}{A_{\mathrm{s}}^{2}} \frac{Q^{2}}{2 g}$,

where $l_{\mathrm{d}}$ and $D$ denote the length and the diameter of the discharging pipe, respectively, and $\lambda, \zeta_{\mathrm{v}}, \zeta_{\mathrm{e}}$ and $\zeta_{\mathrm{i}}$ are the friction factors.

The relationship between the pump head $H$ and the above mentioned hydraulic losses is written as

$$
H=h_{\mathrm{a}}+h_{\mathrm{f}}+h_{\mathrm{v}}+h_{\mathrm{e}}+h_{\mathrm{d}}+h_{\mathrm{i}} .
$$

When Eq. (7) is linearlized by substituting the first and second equations of Eq. (2) and expressed in the dimensionless form using Eq. (4), an equation with process coefficients $C_{\mathrm{a}}$ and $C_{\mathrm{f}}$ is obtained:

$$
\Delta \psi=C_{\mathrm{a}}(\mathrm{d} \phi / \mathrm{d} \tau)+C_{\mathrm{f}} \Delta \phi,
$$

where

$$
C_{\mathrm{a}}=\frac{2 l_{\mathrm{d}}}{r_{2}}, \quad C_{\mathrm{f}}=2 A_{\mathrm{d}}^{2}\left(\frac{\lambda l_{\mathrm{d}}}{A_{\mathrm{d}}^{2} D}+\frac{\zeta_{\mathrm{v}}+\zeta_{\mathrm{e}}+1}{A_{\mathrm{d}}^{2}}+\frac{\zeta_{\mathrm{i}}}{A_{\mathrm{s}}^{2}}\right) \bar{\phi} .
$$

The term $\tau$ in Eq. (8) denotes a dimensionless time defined as $\tau=\bar{\omega} t$.

\section{Calculation of Process Coefficients}

When the time-averaged values of the head $\bar{H}$, the flow rate $\bar{Q}$ and the angular velocity $\bar{\omega}$ are calculated from the variables measured over a duration of the sampling time, dimensionless deviations from the averages $\Delta \psi, \Delta \phi$ and $\Delta \omega / \bar{\omega}$ are obtained. The time derivative $\mathrm{d} \phi / \mathrm{d} \tau$ is estimated by numerical difference schemes. The values of process coefficients $C_{\mathrm{r}}, C_{\mathrm{q}}, C_{\mathrm{a}}$ and $C_{\mathrm{f}}$ are then calculated by substituting $\Delta \psi, \Delta \phi, \Delta \omega / \bar{\omega}$ and $\mathrm{d} \phi / \mathrm{d} \tau$ into Eqs. (3) and (8).

In this study, the sampling time is $5 \mathrm{~s}$, and Eqs. (3) and (8) are solved by the least-squares method.

\section{Classification of Process Coefficients by Neural Network}

To detect running conditions $\mathrm{F} 0-\mathrm{F} 2$ (Table I), a procedure which classifies the values of $C_{\mathrm{r}}, C_{\mathrm{q}}, C_{\mathrm{a}}$ and $C_{\mathrm{f}}$ according to learning data sets $\left(\phi, C_{\mathrm{r}}, C_{\mathrm{q}}\right.$, $\left.C_{\mathrm{a}}, C_{\mathrm{f}}\right)$ is used. The learning data sets have been obtained before the detection. In this paper, a method employing a multi-layer neural network for the classification is proposed.

Figure 4 shows the architecture of a multi-layer neural network (Rumelhart and David, 1989) composed of $L$ layers; an input layer, hidden layers and an output layer. The input and output layers consist of five and two units, respectively. In the hidden layers, the number of layers $L-2$ and the number of units $N$ are changeable. The outputs from the units in one layer are transmitted to the units in another layer through synapse.

The flow rate $\bar{\phi}$ and the process coefficients $C_{\mathrm{r}}$, $C_{\mathrm{q}}, C_{\mathrm{a}}$ and $C_{\mathrm{f}}$ are fed into the input layer. The unit in layer $l$ receives inputs from the units in layer $l-1$. The net input to the $j$ th unit in layer $l, n_{l, j}$, is determined as (Rumelhart and David, 1989):

$$
n_{l, j}=\sum_{i=1}^{N} w_{l, j, i} \mathrm{O}_{l-1, i} \quad(2 \leq l \leq L),
$$




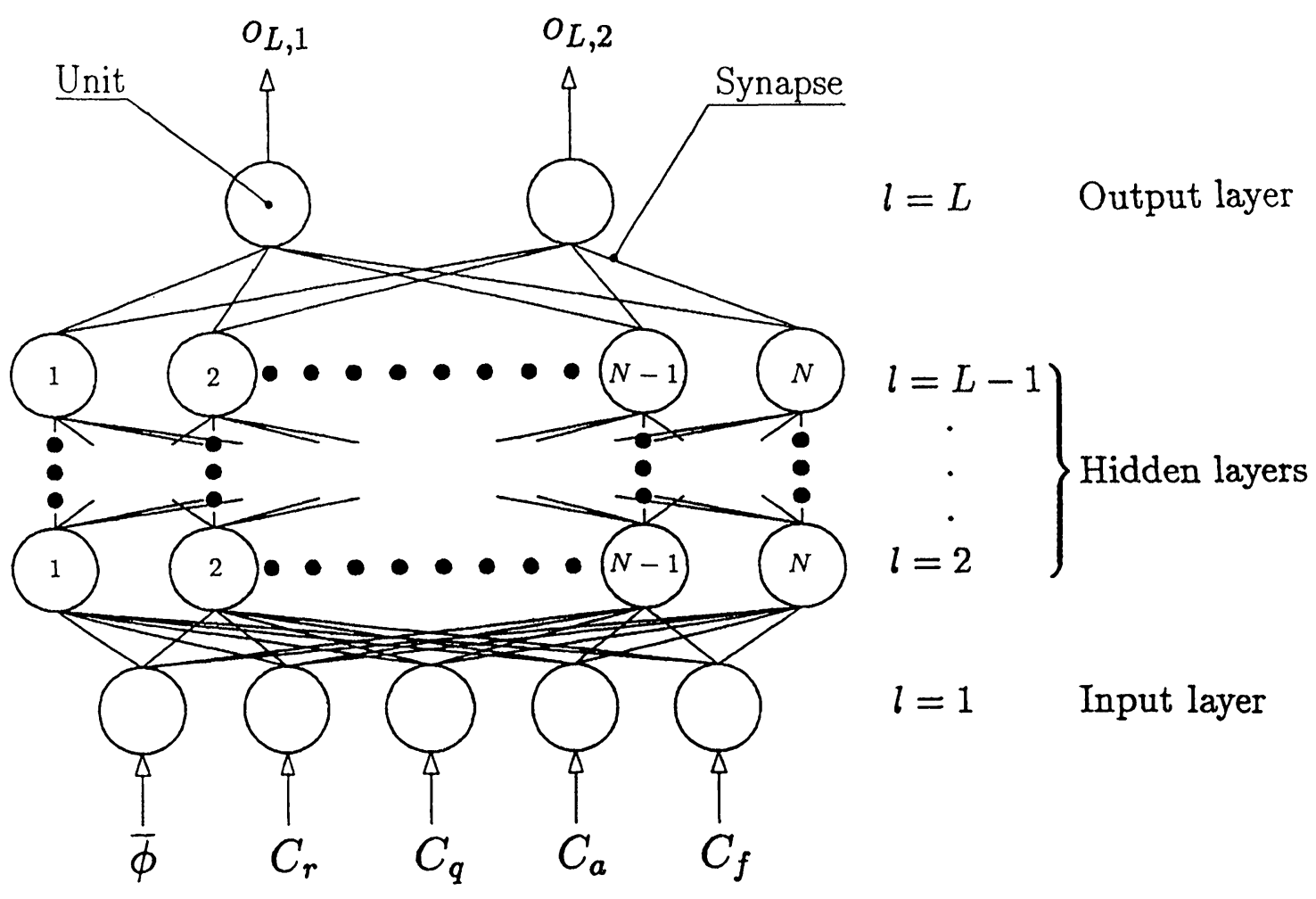

FIGURE 4 Architecture of neural network.

where $w_{l, j, i}$ denotes the weight connecting the $i$ th unit in layer $l-1$ to the $j$ th unit in layer $l$, and $\mathrm{o}_{l-1, i}$ is the output of the $i$ th unit in layer $l-1$.

The output of the $j$ th unit in layer $l, \mathrm{o}_{l, j}$, is given by the following equations (Rumelhart and David, 1989):

$$
\mathrm{o}_{l, j}= \begin{cases}n_{l, j} & (l=1), \\ 1 /\left[1+\exp \left(-n_{l, j}\right)\right] & (2 \leq l \leq L) .\end{cases}
$$

In the fault diagnostic method for the pump running conditions proposed in this paper, the running conditions are detected from the values of the outputs $o_{L, 1}$ and $o_{L, 2}$. It is given that $o_{L, 1}$ and $\mathrm{o}_{L, 2}$ should take the target values $f_{1}$ and $f_{2}$, respectively, for pump running conditions $\mathrm{F} 0-\mathrm{F} 2$ (as shown in Table II), when $\bar{\phi}, C_{\mathrm{r}}, C_{\mathrm{q}}, C_{\mathrm{a}}$ and $C_{\mathrm{f}}$ are fed into the neural network. This prescription is realized by a learning algorithm (Hush and Horne,
TABLE II Running conditions and outputs

\begin{tabular}{lccc}
\hline & $\mathrm{F} 0$ & $\mathrm{~F} 1$ & $\mathrm{~F} 2$ \\
\hline$f_{1}\left(\right.$ target of $\left.\mathrm{o}_{L, 1}\right)$ & 0 & 0 & 1 \\
$f_{2}\left(\right.$ target of $\left.\mathrm{o}_{L, 2}\right)$ & 0 & 1 & 1 \\
\hline
\end{tabular}

1993), which specifies the values of weight $w_{l, j, i}$ in Eq. (10). When some learning data sets $\boldsymbol{x}_{p}=\left(\bar{\phi}, C_{\mathrm{r}}\right.$, $C_{\mathrm{q}}, C_{\mathrm{a}}, C_{\mathrm{f}}$ ) are known for every running condition listed in Table $\mathrm{I}$, the values of the weight $w_{l, j, i}$ can be determined by minimizing the following error function $E$ (Hush and Horne, 1993):

$$
E=\frac{1}{2 P} \sum_{p=1}^{P} \sum_{j=1}^{2}\left[\mathrm{o}_{L, j}\left(\boldsymbol{x}_{p}\right)-f_{j}\left(\boldsymbol{x}_{p}\right)\right]^{2},
$$

where $o_{L, j}\left(\boldsymbol{x}_{p}\right)$ and $f_{j}\left(\boldsymbol{x}_{p}\right)$ denote the values of $\mathrm{o}_{L, j}$ and $f_{j}$ for the learning data set $\boldsymbol{x}_{p}$, respectively, and $P$ is the number of $\boldsymbol{x}_{p}$. 
In this study, a common back-propagation algorithm (Hush and Horne, 1993) is employed for minimization of the error function $E$.

\section{RESULTS AND DISCUSSION}

\section{Pump Performance and Process Coefficients}

Figure 5 shows the pump performance, where the results for three running conditions $(\mathrm{F} 0, \mathrm{~F} 1, \mathrm{~F} 2)$ are superimposed. The dimensionless head $\psi$, the dimensionless shaft power $\lambda$ and the efficiency $\eta$ are plotted against the dimensionless flow rate $\bar{\phi}$. The head $\psi$ and the efficiency $\eta$ for the blocked running condition (F1) are lower than for the normal condition (F0), though the shaft power $\lambda$ for F1 is slightly higher than for F0. The difference in the head is larger at the higher flow rate.

Though the head $\psi$ and the efficiency $\eta$ for the combined condition of blockage and impedance (F2) are quite lower than for F0 and F1, the shaft power $\lambda$ for F2 is almost the same as for F0 and F1. It is, therefore, difficult to detect the running conditions by comparing their shaft powers.

The process coefficients $C_{\mathrm{r}}, C_{\mathrm{q}}, C_{\mathrm{a}}$ and $C_{\mathrm{f}}$ are plotted against the flow rate $\bar{\phi}$ in Fig. 6. The coefficient $C_{\mathrm{r}}$ strongly depends on $\phi$. No significant difference is found between $C_{\mathrm{q}}$ and $C_{\mathrm{f}}$. This is because both coefficients have relation to the deviation of the flow rate. The coefficient $C_{\mathrm{a}}$ is independent of $\phi$ as well as the running conditions. Because the value of $C_{\mathrm{a}}$ is determined only from the outer radius of the impeller $r_{2}$ and the length of the discharging pipe $l_{\mathrm{d}}$ as seen in Eq. (9).

\section{Detection of Running Condition}

When the coefficients $C_{\mathrm{r}}, C_{\mathrm{q}}, C_{\mathrm{a}}$ and $C_{\mathrm{f}}$ together with the flow rate $\phi$ (Fig. 6) are used as the learning data sets $\boldsymbol{x}_{p}$ for Eq. (12), the neural network can be trained so that the outputs $\mathrm{o}_{L, 1}$ and $\mathrm{o}_{L, 2}$ take their target values in accordance with the pump running conditions (Table II).

Figure 7 plots the outputs $o_{L, 1}$ and $o_{L, 2}$ of a neural network against the flow rate $\bar{\phi}$. The

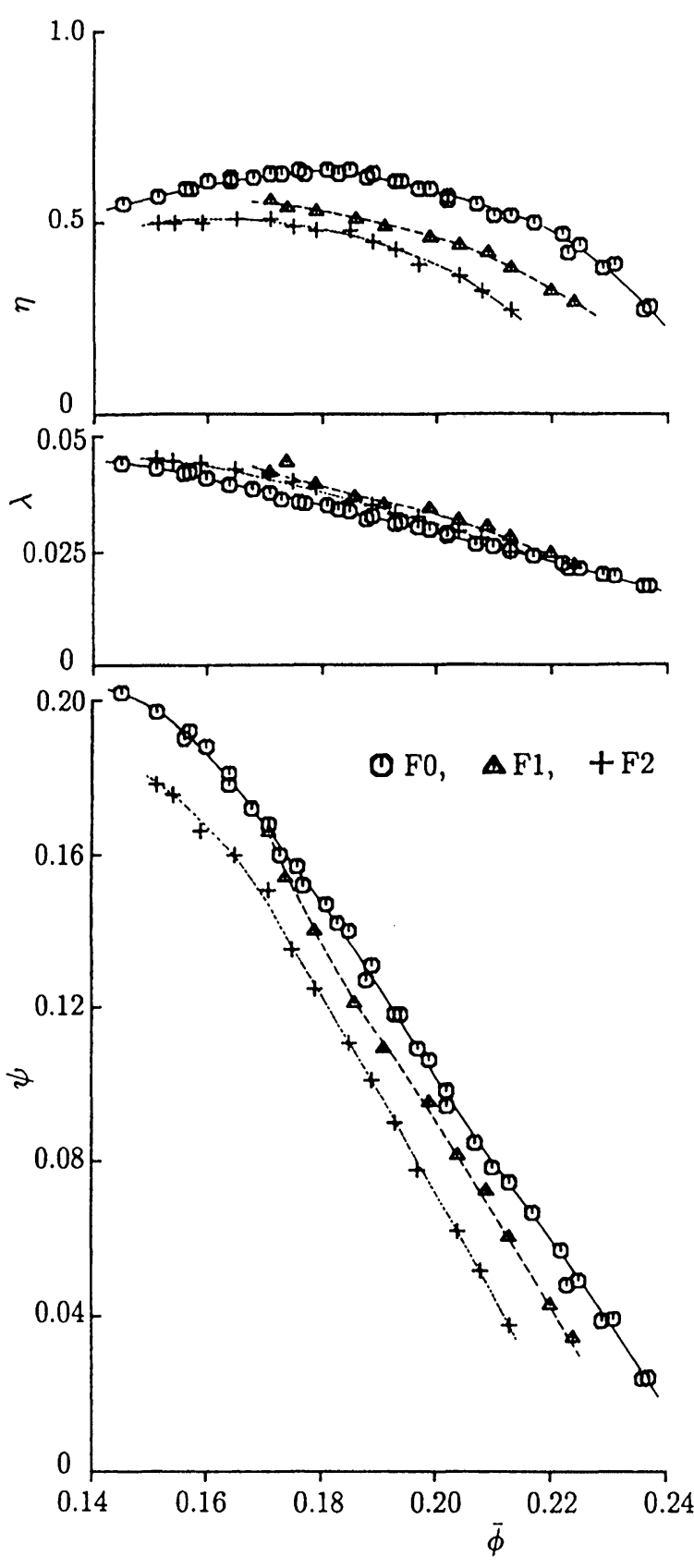

FIGURE 5 Pump performance.

numbers of the layers $L$ and units in hidden layers $N$ of the neural network are 3 and 5 , respectively. The results for conditions which are normal (F0), blocked (F1), blocked and impeded (F2) are shown 


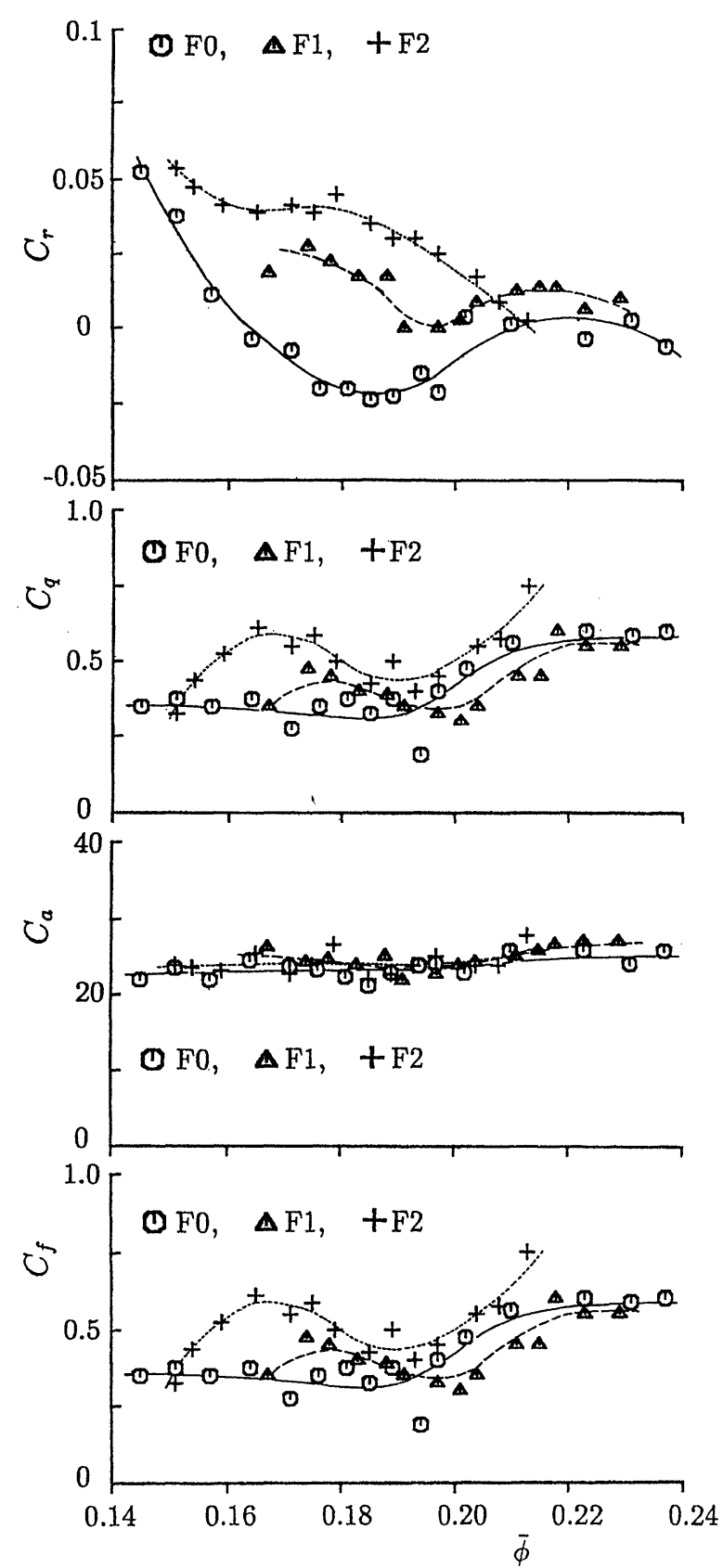

FIGURE 6 Process coefficients.

in Figs. 7(a), (b) and (c), respectively. For the conditions $\mathrm{F} 0$ and $\mathrm{F} 2$, the outputs $\mathrm{o}_{L, 1}$ and $\mathrm{o}_{L, 2}$ are very close to their own targets, showing that the neural network clearly detects these running conditions. As the output $\mathrm{o}_{L, 1}$ for the condition F1
O $o_{L, 1}, \quad \times o_{L, 2}$

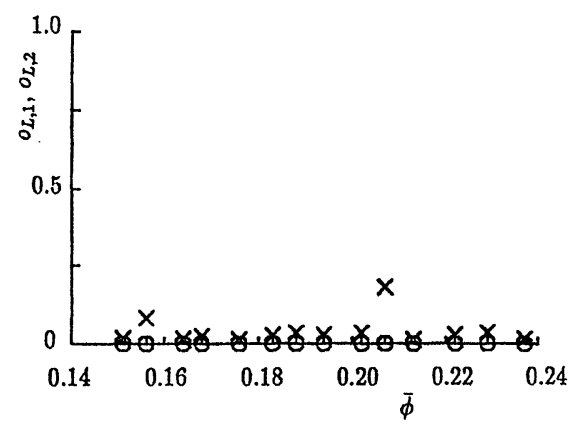

(a) Normal F0

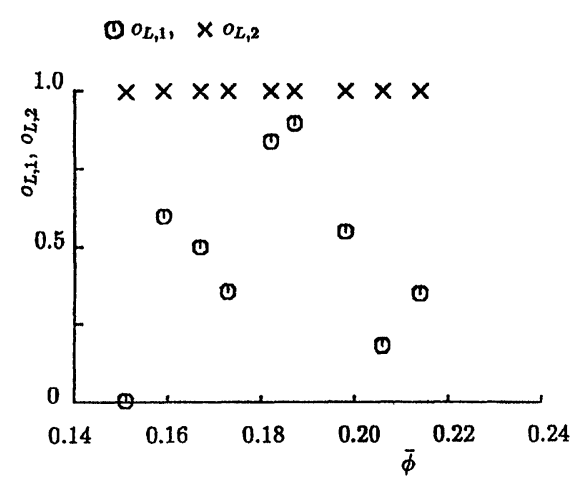

(b) Blocked F1

O $o_{L, 1}, \quad \times o_{L, 2}$

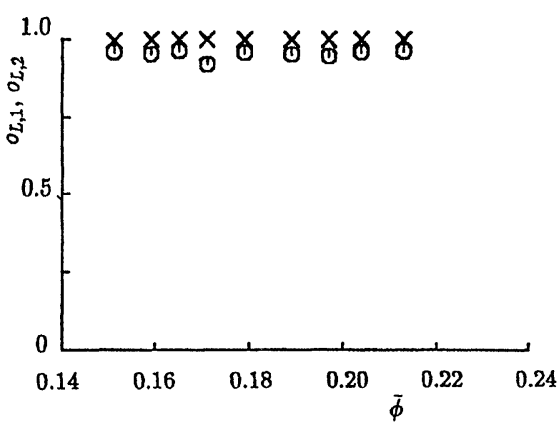

(c) Blocked and impeded F2

FIGURE 7 Detection by neural network of $L=3, N=5$.

disperses in the wide range between 0 to 1 , the condition is not completely detectable.

Figure 8 shows the results obtained by a neural network of $L=3$ and $N=10$. The outputs for the conditions $\mathrm{F} 0$ and $\mathrm{F} 2$ are almost the same as those 


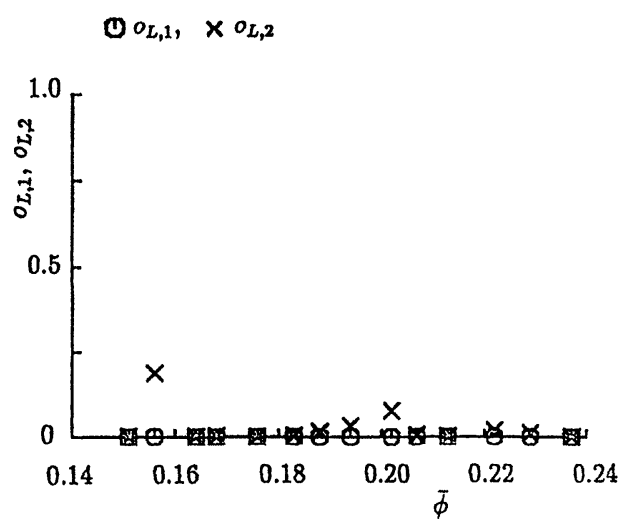

(a) Normal F0

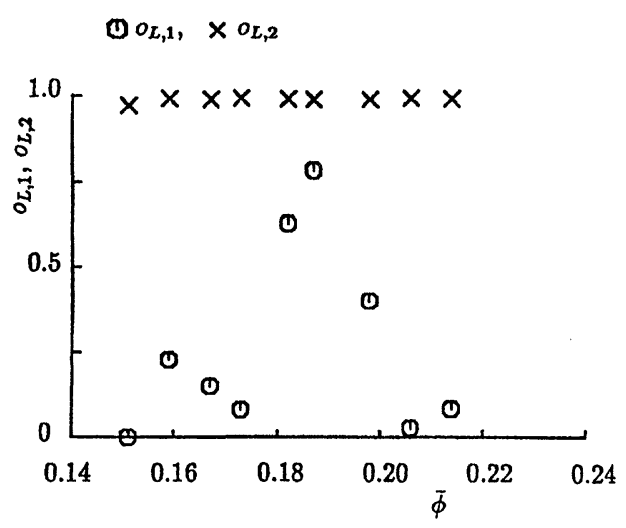

(b) Blocked F1

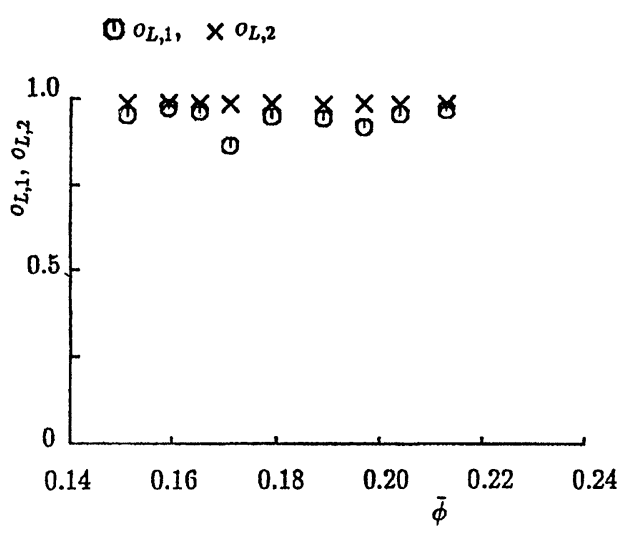

(c) Blocked and impeded F2

FIGURE 8 Detection by neural network of $L=3, N=10$.

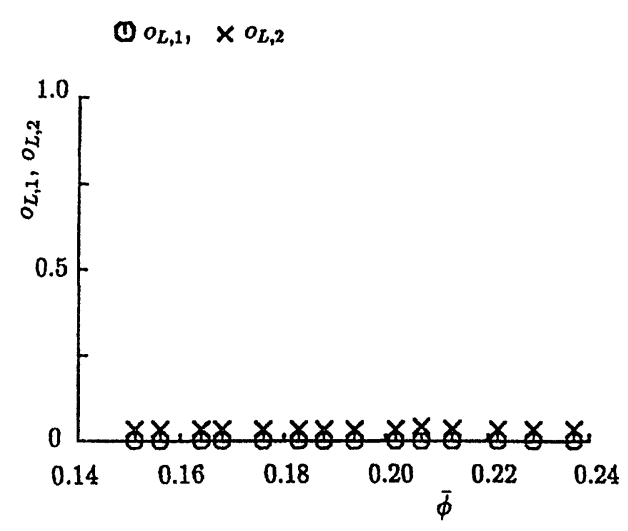

(a) Normal F0

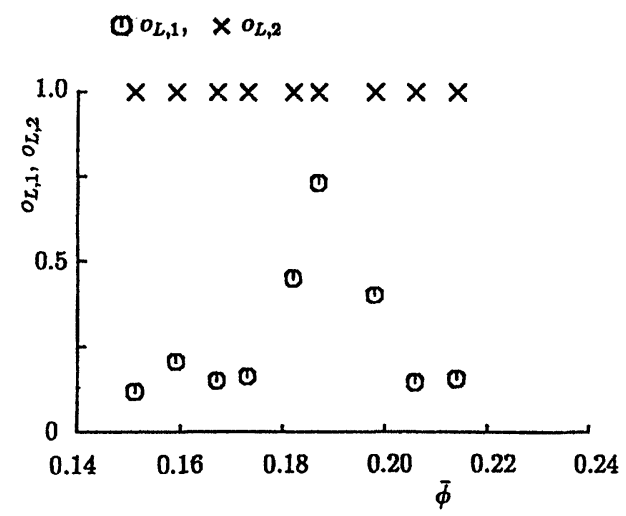

(b) Blocked F1

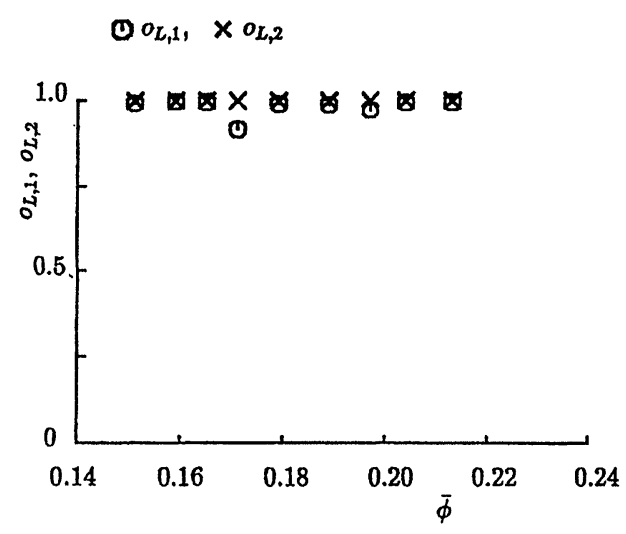

(c) Blocked and impeded F2

FIGURE 9 Detection by neural network of $L=4, N=5$. 
in Fig. 7. The output $\mathrm{o}_{L, 1}$ for $\mathrm{F} 1$ approaches the target value $(0)$ in the whole range of $\bar{\phi}$, indicating the increase in the accuracy of detection.

Figure 9 plots the results by $(L=4, N=5)$. Since most of $\mathrm{o}_{L, 1}$ for the condition $\mathrm{F} 1$ are less than 0.44 , the condition is detectable by the present neural network

\section{CONCLUSIONS}

A fault diagnostic method for pump running conditions was proposed. In the method, the pump head and hydraulic losses in the pump stations are modeled by two equations, and the values of the coefficients in the equations are determined from measurable output variables, and then the running conditions are detected by classifying the coefficient values. A multi-layer neural network is employed in the classification.

The method was applied to a drainage pump station to specify the running conditions. The accuracy of detection is improved by increasing the numbers of the hidden layers and their units. It was confirmed that the running conditions are detectable by a neural network with $L=4$ and $N=3$.

\section{NOMENCLATURE}

$\begin{array}{ll}A & : \text { sectional area } \\ C_{\mathrm{a}}, C_{\mathrm{f}}, C_{\mathrm{q}}, C_{\mathrm{r}} & : \text { process coefficients } \\ D & : \text { diameter of discharging pipe } \\ f_{j} & : \text { target value of neural network } \\ g & : \text { acceleration of gravity } \\ H & : \text { pump head }=\left(p_{\mathrm{d}}-p_{\mathrm{s}}\right) / \rho g+ \\ & \left(V_{\mathrm{d}}^{2}-V_{\mathrm{s}}^{2}\right) / 2 g+z_{\mathrm{d}}-z_{\mathrm{s}} \\ L & : \text { shaft power or number of layers in } \\ & \text { neural network } \\ n_{l, i} & : \text { net input to } i \text { th unit in layer } l \\ N & : \text { number of units in a hidden layer } \\ \mathrm{o}_{l, i} & : \text { output of } i \text { th unit in layer } l \\ p & : \text { absolute static pressure } \\ Q & : \text { volumetric flow rate } \\ r_{2} & : \text { outer radius of impeller } \\ t & : \text { time }\end{array}$

$u_{2} \quad$ : peripheral speed of impeller $=r_{2} \bar{\omega}$

$V \quad$ : velocity of water

$w_{l, j, i}:$ weight connecting unit

$\mathbf{x}_{p} \quad$ : learning data set $=\left(\bar{\phi}, C_{\mathrm{r}}, C_{\mathrm{q}}, C_{\mathrm{a}}, C_{\mathrm{f}}\right)$

$z \quad$ : elevation from bottom of tank

$\eta \quad$ : pump efficiency $=\rho g Q H / L$

$\lambda$ : dimensionless expression of shaft power $=L /\left(\rho A_{\mathrm{d}} u_{2}^{3} / 2\right)$

$\rho \quad$ : density of water

$\tau \quad:$ dimensionless time $=\bar{\omega} t$

$\phi \quad$ : dimensionless expression of flow rate $=Q$ / $A_{\mathrm{d}} u_{2}$

$\psi \quad$ : dimensionless expression of pump head $=$ $H /\left(u_{2}^{2} / 2 g\right)$

$\omega \quad$ : angular velocity of impeller

\section{Subscripts}

d : pump outlet

s : pump inlet

\section{Superscript}

- $\quad$ : time averaged

\section{References}

Friedrichsen, U. 1993. Investigations on Automatization of Drainage Pump Stations, Dissertation, Technical University of Berlin (in German)

Geiger, G. 1984. Fault Identification of a Motor-Pump System Using Parameter Estimation and Pattern Classification, Proceedings of 9th IFAC Congress, Budapest.

Hush, D.R. and Horne, B.G. 1993. Progress in Supervised Neural Networks, IEEE Signal Processing Magazine, January, pp. 8-39.

Isermann, R. 1984. Process Fault Detection Based on Modeling and Estimation Methods - A Survey, Automatica, 20(4), pp. 387-404.

Isermann, R. and Freyermuth, B. 1991a. Process Fault Diagnosis Based on Process Model Knowledge - Part I: Principles for Fault Diagnosis With Parameter Estimation, Trans. ASME, J. Dynamic Systems, Measurement and Control, 113(4), pp. 620-626.

Isermann, R. and Freyermuth, B. 1991b. Process Fault Diagnosis Based on Process Model Knowledge - Part II: Case Study Experiments, Trans. ASME, J. Dynamic Systems, Measurement and Control, 113(4), pp. 627-633.

Nold, S. and Isermann, R. 1988. Model Based Fault Detection for Centrifugal Pumps and A. C. Drives, Proceedings of 11th IMEKO World Congress, Houston.

Rumelhart, D.E. and David, E. 1989. Parallel Distributed Processing, Vol. 1: Foundations, The MIT Press, Cambridge, pp. 318-362. 


\section{ait \\ ENERGY MATERIALS}

M A N E Y publishing

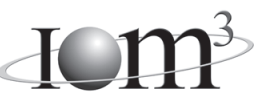

\section{Materials Science \& Engineering for Energy Systems}

Maney Publishing on behalf of the Institute of Materials, Minerals and Mining

The Institute of Materials, Minerals \& Mining

Economic and environmental factors are creating ever greater pressures for the efficient generation, transmission and use of energy. Materials developments are crucial to progress in all these areas: to innovation in design; to extending lifetime and maintenance intervals; and to successful operation in more demanding environments. Drawing together the broad community with interests in these areas, Energy Materials addresses materials needs in future energy generation, transmission, utilisation, conservation and storage. The journal covers thermal generation and gas turbines; renewable power (wind, wave, tidal, hydro, solar and geothermal); fuel cells (low and high temperature); materials issues relevant to biomass and biotechnology; nuclear power generation (fission and fusion); hydrogen generation and storage in the context of the 'hydrogen economy'; and the transmission and storage of the energy produced.

As well as publishing high-quality peer-reviewed research, Energy Materials promotes discussion of issues common to all sectors, through commissioned reviews and commentaries. The journal includes coverage of energy economics and policy, and broader social issues, since the political and legislative context influence research and investment decisions.

\section{CALL FOR PAPERS}

Contributions to the journal should be submitted online at http://ema.edmgr.com

To view the Notes for Contributors please visit: www.maney.co.uk/journals/notes/ema

Upon publication in 2006, this journal will be available via the Ingenta Connect journals service. To view free sample content online visit: www.ingentaconnect.com/content/maney

For further information please contact:

Maney Publishing UK

Tel: +44 (0)113 2497481 Fax: +44 (0)1132486983 Email: subscriptions@maney.co.uk

or

Maney Publishing North America

Tel (toll free): 8662975154 Fax: 6173546875 Email: maney@maneyusa.com

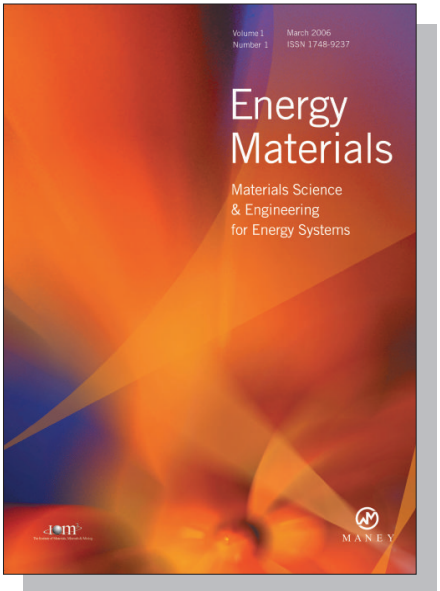

EDITORS

Dr Fujio Abe

NIMS, Japan

Dr John Hald, IPL-MPT, Technical University of Denmark, Denmark

Dr R Viswanathan, EPRI, USA

\section{SUBSCRIPTION INFORMATION}

Volume 1 (2006), 4 issues per year

Print ISSN: 1748-9237 Online ISSN: 1748-9245

Individual rate: $£ 76.00 / U S \$ 141.00$

Institutional rate: $£ 235.00 /$ US $\$ 435.00$

Online-only institutional rate: $£ 199.00 / U S \$ 367.00$

For special $\mathrm{IOM}^{3}$ member rates please email

subscriptions@maney.co.uk

\section{For further information or to subscribe online please visit www.maney.co.uk}



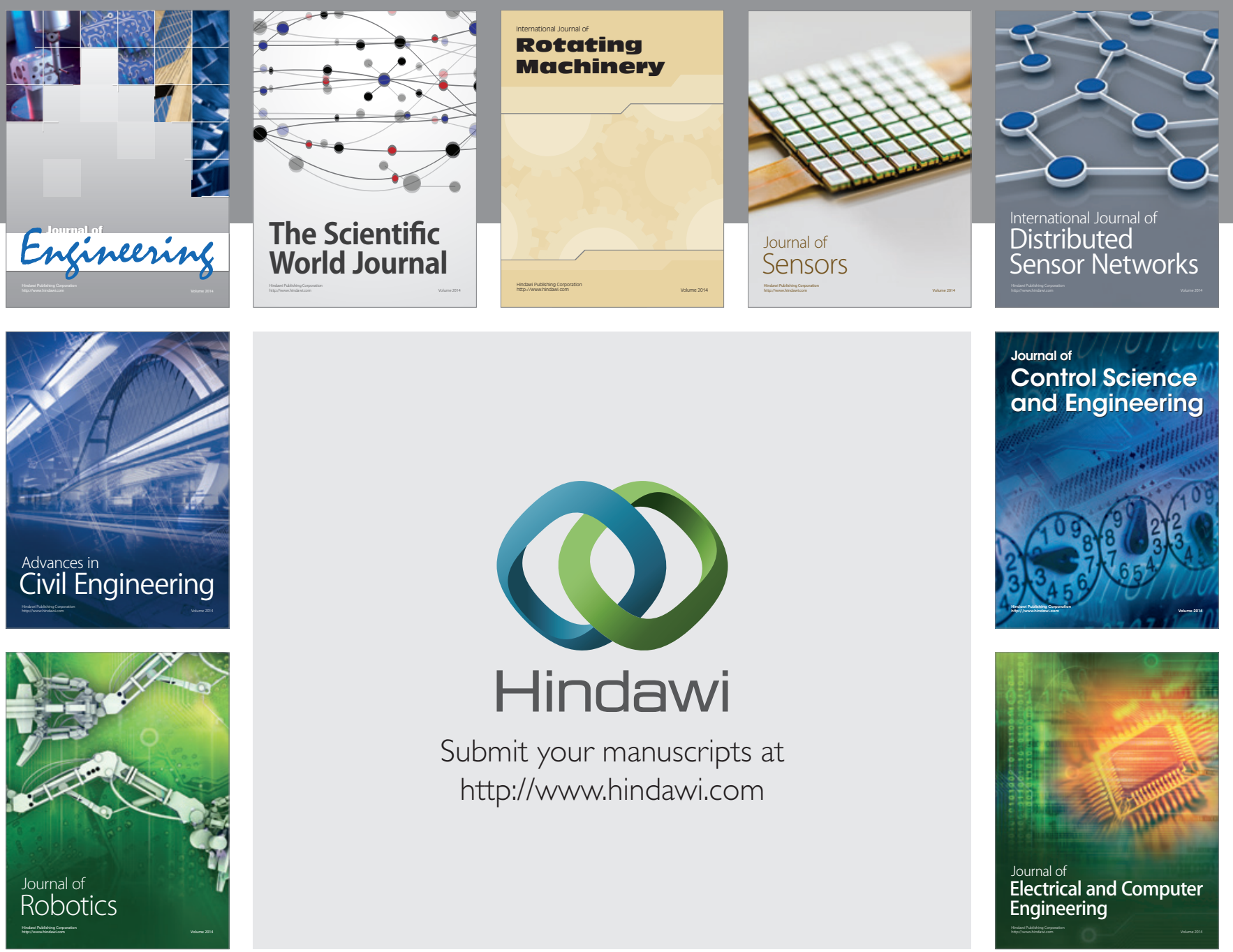

Submit your manuscripts at

http://www.hindawi.com
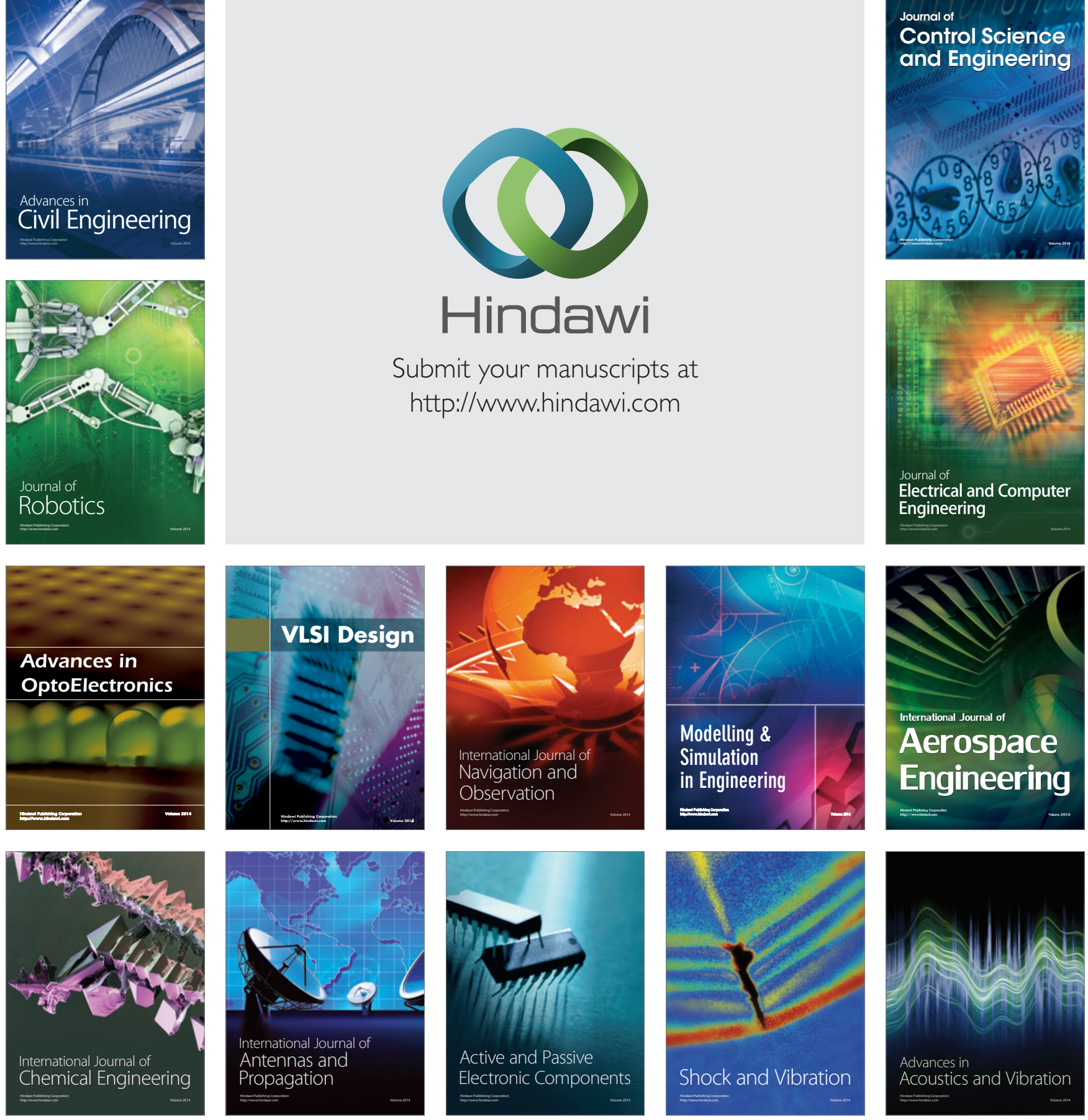